\title{
Treatment of Patients With Hepatitis C Virus and Kidney Diseases
}

\section{Necati Örmeci*}

Ankara University Medical School, Department of Gastroenterology, Ankara, Turkey

\section{Abstract}

HCV is an important global health and economic problem through direct and indirect medical cost associated with managing liver disease, decreased work productivity. A hundred eighty million people are infected in the world. HCV is associated with the increasing liver related and all causes of mortality. Both HCV and Chronic Kidney Disease (CKD) have a negative impact on both morbidity and mortality.

The aim of this article is to reveal the close relationship between HCV and CKD, and to review the studies related with treatment of patients with $\mathrm{HCV}$ and different stages of CKD. Clinical use of Direct Antiviral Agents (DAAs) for the treatment in patients with HCV infection revolutionized the increase of sustained virological response (SVR), decreasing the duration of treatment and severe adverse events. Treatment of HCV infection in chronic renal impairment is reviewed in this article.

\section{Publication History:}

Received: December 29, 2017

Accepted: March 29, 2018

Published: March 31, 2018

\section{Keywords:}

Diagnosis of Acute

Pancreatitis,therapeuticrole of $\mathrm{ERCP} / \mathrm{ES}$-mininvasive surgery in severe pancreatitis

In conclusion, the treatment with DAAs is effective more than $90 \%$ and safe in patients with HCV infection and CKD. According to the stage of CKD, HCV infection should be treated.

\section{Background}

Hepatitis $\mathrm{C}$ virus (HCV) is an enveloped virus with a $9.6 \mathrm{~kb}$ single stranded RNA genome. Six HCV genotypes and a large number of subtypes have been identified [1]. It is an important global health and economic problem. A hundred eighty million people are infected in the world [2]. On one hand, two thirds of the patients with acute $\mathrm{HCV}$ infection become chronically ill, and may progress to having liver cirrhosis (LC) in fifteen to twenty years. One to three per cent of patients with LC may have hepatocellular carcinoma every year [3]. On the other hand HCV may cause an extrahepatic manifestation such as mixed cryoglobulinemia, chronic kidney disease, porphyria cutanea tarda, and type 2 diabetes mellitus, rheumatoid -like nondestructive inflammatory arthritis and depression [4-6] (able 1). In addition to clinical outcomes, HCV has an important impact on economic burden through direct and indirect medical cost associated with managing liver disease, decreased work productivity [7]. HCV is associated with the increasing liver-related and all causes of mortality [8].

\begin{tabular}{|c|c|}
\hline $\begin{array}{l}\text { A-Hepatic } \\
\text { Manifestations }\end{array}$ & B-Extra hepatic Manifestations \\
\hline $\begin{array}{l}{ }^{*} \text { Acute hepatitis C } \\
\text { infection }\end{array}$ & ${ }^{\star}$ Proteinuria \\
\hline $\begin{array}{l}{ }^{*} \text { Chronic Hepatitis C } \\
\text { infection }\end{array}$ & ${ }^{\star}$ Mixed cryoglobulinamia \\
\hline${ }^{\star}$ Liver Cirrhosis & $\begin{array}{l}{ }^{*} \text { Membranoproliferative } \\
\text { glomerulonephritis }\end{array}$ \\
\hline $\begin{array}{l}{ }^{*} \text { Decompensated liver } \\
\text { cirrhosis }\end{array}$ & $\begin{array}{l}{ }^{\star} \text { Mesangial proliferative and focal } \\
\text { proliferative glomerulonephritis }\end{array}$ \\
\hline \multirow{5}{*}{$\begin{array}{l}{ }^{\star} \text { Hepatocellular } \\
\text { Carcinoma }\end{array}$} & ${ }^{*}$ Ig A nephropathy \\
\hline & ${ }^{*}$ Membranous Glomerulonephritis \\
\hline & ${ }^{*}$ Polyarthritisnodosa \\
\hline & $\begin{array}{l}{ }^{*} \text { Insulin resistance and Type } 2 \\
\text { diabetes Mellitus }\end{array}$ \\
\hline & ${ }^{*}$ Transplant glomerulopathy \\
\hline
\end{tabular}

Table 1: Hepatic and extra hepatic manifestations of HCV infection
Both HCV and Chronic Kidney Disease (CKD) have a negative impact both on morbidity and mortality. Clinical use of Direct Antiviral Agents (DAAs) for the treatment of patients with HCV infection revolutionized the increase of sustained virological response (SVR), decreasing the duration of treatment and severe adverse events.

The aim of this article is to reveal the close relationship between $\mathrm{HCV}$ and CKD, and to review the studies related with the treatment of patients with HCV and different stages of CKD.

\section{How HCV Infection Influences the Kidney}

In one study, long-term follow-up of 5737 patients with HCV infection compared to 11228 healthy control patients showed that HCV was associated with the increase liver-related and all causes of mortality [9]. HIV coinfection, diagnosis of drug use, coronary artery disease, stroke, diabetes mellitus, peripheral vascular diseases, depression and anemia are independent risk factors for mortality [9]. In the Dialysis Outcomes and Practice Patterns (DOPPS) Study, 16720 patients which have maintenance hemodialysis were followed up for five years. The crude 1 year mortality rates were found $6.6 \%$ in Japan, $15.6 \%$ in Europe, and $21.7 \%$ in the USA [10]. In one metaanalysis, which has 14 observational studies, Anti-HCV antibody was found to be an independent and significant risk factor for death in 145,608 patients on maintenance hemodialysis. Adjusted relative risk for all causes of mortality was 1.36 (95\% CI; $1.25-1.47)$ and also adjusted relative risk for cardiovascular mortality was 1.26 (95\% CI; 1.10-1.45) [11].

In a nationwide cohort study from Taiwan, 9430 newly diagnosed HCV patients and randomly selected 37720 healthy people were compared in terms of incidence rate and incident CKD. It was found that the frequency of CKD was 1.66 -fold higher in the HCV than

"Corresponding Author: Prof. Necati Örmeci, Ankara University Medical School, Department of Gastroenterology, Ankara, Turkey; E-mail: normeci@yahoo.com

Citation: Örmeci N (2018) Treatment of Patients With Hepatitis C Virus and Kidney Diseases. Int J Gastroenterol Disord Ther 5: 138. doi: https://doi. org/10.15344/2393-8498/2018/138

Copyright: (c) 2018 Örmeci. This is an open-access article distributed under the terms of the Creative Commons Attribution License, which permits unrestricted use, distribution, and reproduction in any medium, provided the original author and source are credited. 
the non-HCV cohort (5.46 compared with 3.43 per 1000 person per year). The risk for CKD in patients with HCV was higher in diabetes, hyperlipidemia and cirrhosis. This results showed that $\mathrm{HCV}$ infection is associated with the increased risk for CKD [12].

In a meta-analysis which has 18 observational studies, anti $\mathrm{HCV}$ antibody was found to be increased adjusted relative to the risk for all causes of mortality and all causes of graft loss in 133,530 unique renal transplant recipients. Adjusted relative risk for all causes of mortality was 1.85 with a $95 \%$ confidence interval; $1.49-2.31 \quad(\mathrm{p}<0.0001)$. Adjusted relative risk for all causes of graft loss was 1.76 (95\% CI; $1.46-2.11 ; \mathrm{p}<0.0001$ ) [13]. In another meta-analysis performed by the same study group, 8 observational studies, 105,462 unique patients with HIV and HCV were evaluated in terms of glomerular filtration rate, proteinuria. It was found that there was increased risk of reduced glomerular filtration rate (Relative risk 1.64 (95 \% CI; 1.28-2.0; $\mathrm{p}<0.001)$ and increased risk for proteinuria, relative risk $1.23(95 \%$ CI; 1.18-1.28; $\mathrm{P}<0.001)[14]$.

According to United States Renal Data System, among 474,369 patients, 52,874 persons (11.1\%) had a positive HCV antibody test results. It was shown that the patients with $\mathrm{HCV}$ were associated with a greater than twofold risk for developing end stage renal disease (adjusted hazard rate; $2.80: 95 \%$ confidence interval 2.43-3.23) [15]

\section{How CKD Infection Influences HCV Infection}

In order to standardize the terminology and decide better for the treatment, CKDs were classified by KDIGO [16].

The survival in patients with CKD, stages 1 and 2 , is not different from that of the general population with normal kidney function. The 5-year survival for patients with CKD, stage 3, without HCV infection has been reported to be $76 \%$, for patients with CKD, stage $4,54 \%$. Patients with CKD, stage 5 , have a markedly reduced survival compared with the general population with normal kidney function [17].

\begin{tabular}{|l|l|l|}
\hline & $\begin{array}{l}\text { eGFR }(\mathrm{ml} / \\
\left.\mathrm{min} / 1.73 \mathrm{~m}^{2}\right)\end{array}$ & CKD Stage \\
\hline Normal Renal Function & $\triangleright 89$ & Stage 1 \\
\hline Mild Renal İmpairment & $60-89$ & Stage 2 \\
\hline Moderate Renal İmpairment a & $45-59$ & Stage 3a \\
\hline Moderate Renal İmpairment b & $30-44$ & Stage 3b \\
\hline Severe Renal İmpairment & $15-29$ & Stage 4 \\
\hline End Stage Renal Disease & $<15$ & Stage 5 \\
\hline
\end{tabular}

Table 2: The Classification of Renal Failure [16].

A recent study showed that receiving the liver from Anti HCV positive donors to patients with $\mathrm{HCV}$ does not influence survival, and it is a safety procedure for long-term strategy. Besides that, it results in shortened waiting list of kidney transplantation $[18,19]$.

In one meta-analysis, which has 14 observational studies, the risk for developing CKD/ESRD in 336,227 patients who have HCV infection was compared to uninfected 2,665,631 controls. It was found that the patients with HCV had a $23 \%$ greater risk for developing CKD/ESRD compared to uninfected controls. The risk ratio was 1.23 (95\%, CI; 1.12-1.34). In the subgroup analysis, increased risk for developing CKD/ESRD was found in both Taiwanese and US patients [20].
There is significantly increased risk of mortality, duration of hospitalization, anemia, pain, decreasing of quality of life in patients with end stage renal disease and HCV infection [21]. The prevalence of $\mathrm{HCV}$ infection in patients with chronic renal failure is higher (9.5\% versus $1.6 \%)$ than with uninfected people. Those patients who have maintenance hemodialysis with HCV have also increased risk of mortality compared to uninfected ones because of not only liverrelated complications but also increased cardiovascular [22]. Because of those reasons, HCV infection in patients with renal impairment must be diseases treated. Before the treatment we have to be aware of those conditions:

\section{Level of fibrosis in the liver (F1-F6)}

2. Genotype of HCV (Genotype 1a, 1b, 2,3,4,5,6)

3. Previous treatments (PEG-IFNs, PEG-IFNs+Ribavirin or Direct Acting Antivirals)

4. Co-morbidity (HIV+HCV, HBV+HCV)

5. Drug-drug interactions (Using of Protease inhibitors in liver disease, Sofosbuvir in CKD, Simeprevir and Calcineurin inhibitors)

6. Kidney functions (Stage 2-5)

7. Metabolic clearance of the drugs in order to treat HCV infection.

Sofosbuvir is eliminated from the kidney in $80 \%$. When GFR is decreased less than $30 \mathrm{ml} / \mathrm{min}$, Area under the Curve (AUC) increases by $456 \%$. The dose of Sofosbuvir should be adjusted in CKD, stages 3-5. Dasabuvir is eliminated from gastrointestinal system by $90 \%$. When GFR is decreased less than $30 \mathrm{ml} / \mathrm{min}$, AUC increases by $50 \%$. Daclatasvir, Ledipasvir, Velpatasvir, Simeprevir, Ombitasvir and Elbasvir and Grazoprevir are eliminated mainly from the gastrointestinal system, and AUC will not be changed in renal impairments. Paritaprevir/Ritonavir is eliminated mainly from gastrointestinal system, $2 \%$ from the kidney. When GFR is decreased less than $30 \mathrm{ml} / \mathrm{min}$, AUC increases by 114\% [22].

When patients with HCV infection and CKD, stages 1-3, must be treated, it is not necessary to adjust the doses of DAAs. Those patients can be treated according to AASLD, EASL and APASL guidelines for $\mathrm{HCV}$ infection [23-25]. If patients with HCV infection and CKD, stages $4-5$, are to be treated, we should be aware of elimination ways of the drugs, and we should choose them accordingly.

Four hundred and eight patients with HCV, genotype 1, were treated with the combination of Sofosbuvir $400 \mathrm{md} /$ day and Ledipasvir 90 $\mathrm{mg} /$ day for 12 weeks. Seventy-three out of 408 had liver transplanted. Eighty-two \% of 408 patients had chronic renal impairment with stage 2or 3. SVR rate was $95.9 \%$ [26].

In a comparative study, 1716 patients who had GFR $>45 \mathrm{ml} / \mathrm{min}$ were compared to 73 patients who had GFR $<45 \mathrm{ml} / \mathrm{min}$ in terms of effectiveness of Sofosbuvir $400 \mathrm{mg} /$ day and Ribavirin $800 \mathrm{mg} /$ day; and impact on renal glomerular functions. Seventy-three $\%$ of total 1789 patients had decompensated liver cirrhosis and forty-nine \% of them had liver transplantation. SVR rates were similar, $82 \%$ and $83 \%$. However, patients who had GFR $<45 \mathrm{ml} / \mathrm{min}$ had worsened renal glomerular functions and anemia [27].

Treatment of fiftynaïve patients who are on hemodialysis were randomly treated with PEG interferon $(\mathrm{n}=25)$ and Classical interferon $(n=25)$ for 48 weeks. SVR rates are $48 \%$ and $20 \%$ respectively $(\mathrm{p}=0.07)$. Withdrawal of treatments due to adverse events are $0 \%$ and $20 \%(\mathrm{p}=0.04)[28]$. 
Telaprevir-containing triple therapy had superior efficacy more than PEG-IFN/IFN/ and Ribavirin dual therapy [29]. But today due to common adverse events, those drugs are not recommended for the treatment of HCV infection.

Six patients with HCV, genotype 3, were treated with Sofosbuvir patients had compensated liver cirrhosis, the other two patients had higher than $6,000,000 \mathrm{iu} / \mathrm{ml} \mathrm{HCV}$-RNA levels. SVR rate was $100 \%$ in this retrospective study [30].

Forty-seven patients with renal transplants were treated with sofosbuvir-based regimen. Fourteen sofosbuvir and Ribavirin for 24 weeks. SVR rate was $86 \%$. Twenty-two patients were given sofosbuvir400 mg/day and Ledipasvir $90 \mathrm{mg} /$ day for 12 weeks. Another 12 patients were given sofosbuvir $400 \mathrm{mg} /$ day, Daclatasvir 60 $\mathrm{mg} /$ day, Ribavirin $(\mathrm{n}=3)$ for 24 weeks. SVR rate was $100 \%$. Anemia was seen in $57 \%$ of the patients [31].

Thirty-two patients with CKD, stage 3 (Glomerular filtration rate $\leq 60 \mathrm{ml} / \mathrm{min} \geq 30 \mathrm{ml} / \mathrm{min}$ ) were treated with Elbasvir $50 \mathrm{mg} /$ day, Grazoprevir 100 mg/day for 8-18 weeks with or without Ribavirin. One out of four patients was compensated cirrhotic, $41 \%$ of them were co-infected with HIV. SVR rate for 12 weeks was $97 \%$. There was no improvement of GFR in patients [32].

Two hundred fifty-four patients with HCV infection who had liver transplantation were followed up for 13 years. Chronic renal failure developed in seventy-six (30\%) of them. HCV infection, Glomerular filtration rate before transplantation and being a woman are predictive factors for developing chronic renal failure. Diabetes Mellitus and use of calcineurin inhibitors are causes for developing renal failure. Fiveyear survivals were found $54.6 \%$ and $28.2 \%$ in patients who had not developed and had developed chronic renal failure respectively [33].

Three hundred and twenty-two patients with HCV,genotypeland CKD, stage $3 b 5 \%$,Stage $4-5 ; 2.5 \%$, were treated with combination of asunaprevir $100 \mathrm{mg}$ BID and Daclatasvir $60 \mathrm{mg}$ /day for 12 weeks. SVR rates of Stage 3B and Stage $4-5$ were $88 \%$ and $100 \%$ respectively. Two and one half $\%$ of patients discontinued the treatment. Baseline presence of NS5A resistance associated Variants, previous Simeprevir treatment, HCV-RNA levels before the treatment are predictors for SVR [34].

In a meta-analysis which has 11 studies, 264 patients with $\mathrm{HCV}$ genotype land CKD, stages 4-5 were treated with sofosbuvir based or non-sofosbuvir based regimens. The pooled SVR rate was $93.2 \%$.

SVR rates of Sofosbuvir based and Non-sofosbuvir based regimen were $89.4 \%$ and $94.7 \%$ respectively. The pooled discontinuation rate was $2.2 \%$ [35].

Ten patients with HCV, genotype $1 \mathrm{a}, 1 \mathrm{~b}$ and 4 , were treated with PROD (Paritaprevir, Ritonavir, Ombitasvir and Dasabuvir) regimen. Seven out of ten patients had compensated liver cirrhosis, three patients had treatment experience. SVR rate was $100 \%$. Eighty per cent of patients have side effects [36]. Twenty patients with HCV, genotype 1a $(n=13)$, genotype $1 b(n=7)$, and ESRD, were treated with PROD regimens for 12 weeks. SVR rate was $90 \%$. One patient relapsed, one patient died from a reason other than a drug adverse event. Four patients had anemia because of Ribavirin treatment [37]. $200 \mathrm{mg}$ a day, Daclatasvir $60 \mathrm{mg}$ a day for 12 weeks. Two out of 6

Seventeen patients with chronic renal failure $(\mathrm{GFR}<30 \mathrm{ml} / \mathrm{min})$ were treated with the combination of Simeprevir150mg/day and Sofosbuvir $400 \mathrm{mg} /$ day for 12 weeks. Forty-seven \% of patients were cirrhotic, $24 \%$ of them had F3 fibrosis of the liver. Seventy-six \% of patients had genotype 1a. Four patients (24\%) experienced adverse events such as insomnia, headache and nausea [38].

Thirty-one patients were treated with the combination of Sofosbuvir $400 \mathrm{mg}$ /day and Ledipasvir $90 \mathrm{mg}$ for 12 weeks after kidney transplantation. SVR rate was $97 \%$. Six patients who had proteinuria $500 \mathrm{mg} / \mathrm{dl}$ or more before the treatment had worsened proteinuria during the follow up [39].

Forty-six patients were treated with PROD regimen. Ten out of $46(21.7 \%)$ had CKD, stage $4 ; 30$ out of $46(78.2 \%)$ had CKD, stage $5 ; 17$ out of 46 (36.9\%) had liver cirrhosis. Twenty-one (46\%) patients received Ribavirin.SVR rate was $95.7 \%$. Twenty-seven (58.6 \%) patients received Erythropoietin. Twelve patients had anemia $(\mathrm{Hb}<10 \mathrm{gr} / \mathrm{dl})$. Two patients discontinued the treatment $(4.3 \%)$ due to congestive heart failure and atrial arrhythmias. Doses of the Tacrolimus, levothyroxine, Acenocoumarol were adjusted during the treatment of PROD regimen. When Immunosuppressives, Calcineurin inhibitors, anti- hypertensive, ACE inhibitors, and Calcium channel blockers were used together with PROD regimen, it was better to adjust the doses of those drugs [40].

In the C-Surfer study, 224 patients with HCV, genotype 1 and $\mathrm{CKD}$, stage 4 or 5 were randomized to treat with the combination Grazoprevir $100 \mathrm{mg} /$ day and Elbasvir $50 \mathrm{mg}$ /day for 12 weeks. 179 patients (76\%) were hemodialysis dependent, 122 patients (52\%) had genotype 1a, 189 patients (80\%) were treatment naïve, 14 patients (6 $\%)$ were cirrhotic. SVR rate was $99 \%$. Most common adverse events were headache, nausea and fatigue. One patient had relapse 12 weeks after the treatment [41].

A hundred and four patients with $\mathrm{HCV}$ (genotype 1, 52\%, genotype $2,16 \%$, genotype $3,11 \%$, genotype $4,19 \%$, genotype 5 and $6,2 \%$ ) and CKD (stages 4 and 5) were treated with the combination of Glecaprevir (NS $3 / 4$ blockure) $300 \mathrm{mg} /$ day and pibrentasvir (NS 5A blockure) $40 \mathrm{mg} /$ day for 12 weeks. SVR rate was $98 \%$. Four patients discontinued the treatment because of adverse events. But, three of them had SVR after following up 3 months [42].

\section{Conclusion}

HCV infection and CKD have a negative impact on each other on mortality and morbidity. The treatment with DAAs is effective more than $90 \%$ and safe in patients with HCV infection and CKD.

\section{Competing Interests}

The authors declare that they have no competing interests.

\section{References}

1. Dubuisson J, Helle F, Cocquerel L (2008) Early steps of the hepatitis C virus life cycle. Cellular Microbiology 10: 821-827.

2. Ghany MG, Strader DB, Thomas DL, Seeff LB, American Association for the Study of Liver Diseases, et al. (2009) Diagnosis, management, and treatment of hepatitis C: AN UPDATE. Hepatology 49: 1335-1374.

3. Fattovich G, Llovet JM (2006) Risk factors for hepatocellular carcinoma in HCV-cirrhosis: what we know and what is missing. J Hepatol 44: 10131016.

Int J Gastroenterol Disord Ther

ISSN: 2393-8498

IJGDT, an open access journa

Volume 5. 2018. 138 
4. Younossi Z, Park H, Henry L, Adeyemi A, Stepanova M, et al. (2016) Extrahepatic manifestations of hepatitis C: A meta-analysis of prevalence, quality of life, and economic burden. Gastroenterology 150: 1599-1608.

5. El-Serag HB, Hampel H, Yeh C, Rabeneck L (2002) Extrahepatic manifestations of hepatitis $\mathrm{C}$ among United States male veterans. Hepatology 36: 1439-1445

6. Gheith OAA (2011) Dilemma of HCV Infection in renal transplant recipients. International Journal of Nephrology.

7. Örmeci N, Malhan S, Balık I, Ergör G, Razavi H, et al. (2017) Scenarios to manage the hepatitis $\mathrm{C}$ disease burden and associated economic impact of treatment in Turkey. Hepatol Int 11: 509-516.

8. $\mathrm{Hu} \mathrm{KQ}$, Tong MJ (1999) The long-term outcomes of patients with compensated hepatitis $C$ virus-related cirrhosis and history of parenteral exposure in the United States. Hepatology. 29: 1311-1316.

9. Butt AA, Skanderson M, McGinnis KA, Ahuja T, Bryce CL, et al. (2007) Impact of hepatitis $C$ virus infection and other comorbidities on survival in patients on dialysis. J Viral Hepat 14: 688-696.

10. Pisoni RL, Gillespie BW, Dickinson DM, Chen K, Kutner MH, et al. (2004) The dialysis outcomes and practice patterns study (DOPPS): design, data elements, and methodology. Am J Kidney Dis 44: S7-S15.

11. Fabrizi F, Dixit $V$, Messa $P(2012)$ Impact of hepatitic $C$ on survival in dialysis patients: a link with cardiovascular mortality? Journal of Viral Hepatitis 19 601-607.

12. Chen YC, Lin HY, Li CY, Lee MS, Su YC, et al. (2014) A nationwide cohor study suggests that hepatitis $C$ virus infection is associated with increased risk of chronic kidney disease. Kidney International 85: 1200-1207.

13. Fabrizi F, Penatti A, Messa P, Martin P (2014) Treatment of hepatitis C after kidney transplant: A pooled analysis of observational studies. Journal of Medical Virology 86: 933-940.

14. Fabrizi F, Verdesca S, Messa P, Martin P (2016) Hepatitis C virus Increases the risk of kidney disease among HIV-positive patients: systematic review and meta-analysis. Journal of Medical Virology 88: 487-497.

15. Tsui JI, Vittinghoff E, Shlipak MG, Bertenthal D, Inadomi J, et al. (2007) Association of hepatitis $C$ seropositivity with increased risk for developing end-stage renal disease. Arch Intern Med 167: 1271-1276.

16. Kirsztajn GM, Filho NS, Draibe SA, Netto MV, Thome FS, et al. (2014) Fast reading of the KDIGO 2012: guidelines for evaluation and management of chronic kidney disease in clinical practice. J Bras Nefrol 36: 63-73.

17. Pol S, Jadoul M, Vallet-Pichard A (2017) An update on the management of hepatitis $C$ virus-infected patients with stage 4-5 chronic kidney disease while awaiting the revised KDIGO guidelines. Nephrol Dial Transplant 32 32-35.

18. Morales JM, Campistol JM, Domínguez-Gil B, Andrés A, Esforzado N, et al. (2010) Long-term experience with kidney transplantation from hepatitis $\mathrm{C}$-positive donors into hepatitis C-positive recipients. American Journal of Transplantation 10: 2453-2462.

19. Gallegos-Orozco JF, Kim R, Thiesset HF, Hatch J, Lynch k, et al. (2016) Early results of pilot study using hepatitis $\mathrm{C}$ virus (HCV) positive kidneys to transplant HCV infected patients with end-stage renal disease allowing fo successful interferon-free direct acting antiviral therapy after transplantation 8: 890.

20. Park H, Adeyemi A, Henry L, Stepanova M, Younossi Z, et al. (2015) A meta-analytic assessment of the risk of chronic kidney disease in patients with chronic hepatitis C virus infection. Journal of Viral Hepatitis 22: 897 905

21. Ladino M, Pedraza F, Roth D (2017) Opportunities for treatment of the hepatitis $C$ virus-infected patient with chronic kidney disease. World $J$ Hepatol 9: 833-839.

22. Lens S, Rodriguez-Tajes S, Llovet LP, Maduell F, Londoño MC, et al. (2017) Treating hepatitis $C$ in patients with renal failure. Dig. Dis 35: 339-346.

23. HCV Guidance recommendations for testing, managing and treating hepatitis C. Infectious Diseases Society of America.

24. European association for the study of the liver (2016) EASL recommendations on treatment of hepatitis C 2016. Journal of Hepatology.

25. Omata M, Kanda T, Wei L, Yu ML, Chuang WL, et al. (2016) APASL consensus statements and recommendation on treatment of hepatitis $\mathrm{C}$. Hepatol Int 10: 702-726.

26. Pillai AA, Maheshwari R, Vora R, Norvell JP, Ford R, et al. (2017) Treatment of HCV infection in liver transplant recipients with ledipasvir and sofosbuvir without ribavirin. Aliment PharmacolTher 45: 1427-1432.
27. Saxena V, Koraishy FM, Sise ME, Lim JK, Schmidt M, et al. (2016) Safety and efficacy of sofosbuvir-containing regimens in hepatitis $\mathrm{C}$-infected patients with impaired renal function. Liver Int 36: 807-816.

28. Liu CH, Liang CC, Lin JW, Chen SI, Tsai HB, et al. (2008) Pegylated interferon Alfa-2a versus standart interferon alfa-2a for treatment-naive dialysis patients with chronic hepatitis C: a randomised study. Gut 57: 525530.

29. Basu P, Siriki R, Shah NJ, Farhat S, Mittimani K, et al. (2013) Telaprevir with adjusted dose of ribavirin in naive CHC-G1: efficacy ant treatment in $\mathrm{CHC}$ in hemodialysis population. J Hepatol. 58: S30-S31.

30. Sperl J, Frankova S, Kreidlova M, Merta D, Tothova M, et al. (2017) Combination of sofosbuvir and daclatasvir in the treatment of genotype 3 chronic hepatitis $C$ virus infection in patients on maintenance hemodialysis. Therapeutics and clinical risk management. 13: 733-738.

31. Taneja S, Duseja A, De A, Kumar V, Ramchandran R, et al. (2017) Successful treatment of chronic hepatitis $\mathrm{C}$ infection with directly acting antivirals in renal transplant recipients.

32. Reddy KR, Roth D, Bruchfeld A, Hwang P, Haber B, et al. (2017) Elbasvir/ grazoprevir does not worsen renal function in patients with hepatitis $C$ virus infection and pre-existing renal disease. Hepatology Research 47: 13401345.

33. Ip S, Hussaini T, Daulat A, Partovi N, Erb SR, et al. (2017) Interaction of gender and hepatitis $C$ in risk of chronic renal failure after liver transplantation. Annals of Hepatology 16: 230-235

34. Suda G, Nagasaka A, Yamamoto Y, Furuya K, Kumagai K, et al. (2017) Safety and efficacy of daclatasvir and asunaprevir in hepatitis $C$ virusInfected patients with renal impairment. Hepatol Res 47: 1127-1136.

35. Li T, Qu Y, Guo Y, Wang Y, Wang L, et al. (2017) Efficacy and safety of direct-acting antivirals-based antiviral therapies for hepatitis $C$ Virus patients with stage 4-5 chronic kidney disease: A meta-analysis. Liver International 37: 974-981.

36. Ponziani FR, Siciliano M, Lionetti R, Pasquazzi C, Gianserra L, et al. (2017) Effectiveness of paritaprevir/ritonavir/ombitasvir/dasabuvir in hemodialysis patients with hepatitis $C$ virus infection and advanced liver fibrosis: case reports. Am J Kidney Dis 70: 297-300.

37. Pockros PJ, Reddy KR, Mantry PS, Cohen E, Bennett M, et al. (2016) Efficacy of direct-acting antiviral combination for patients with hepatitis $C$ virus genotype 1 infection and severe renal impairment or end-stage renal disease. Gastroenterology 150: 1590-1598.

38. Nazario HE, Ndungu M, Modi AA (2016) Sofosbuvir and simeprevir in hepatitis $C$ genotype 1-patients with end-stage renal disease on haemodialysis or GFR<30 ml/min. Liver Int 36: 798-801.

39. Lubetzky M, Chun S, Joelson A, Coco M, Kamal L, et al. (2017) Safety and efficacy of treatment of hepatitis $C$ in kidney transplant recipients with directly acting antiviral agents. Transplantation 101: 1704-1710.

40. Muñoz-Gómez R, Rincón D, Ahumada A, Hernández E, Devesa MJ, et al. (2017) Therapy with ombitasvir / paritaprevir / ritonavir plus dasabuvir is effective and safe for the treatment of genotypes 1 and 4 hepatitis $C$ virus $(\mathrm{HCV})$ infection in patients with severe renal impairment: A multicentre experience. J Viral Hepat 24: 464-471.

41. Roth D, Nelson DR, Bruchfeld A, Liapakis A, Silva M, et al. (2015) Grazoprevir plus elbasvir in treatment-naive and treatment-experienced patients with hepatitis $C$ virus genotype 1 infection and stage 4-5 chronic kidney disease (the C-SURFER study): a combination phase 3 study. Lancet 386: 1537-1545

42. Gane E, Lawitz E, Pugatch D, Papatheodoridis G, Brau N, et al. (2017) Glecaprevir and pibrentasvir in patients with $\mathrm{HCV}$ and severe renal impairment. N. Engl J Med 377: 1448-1455. 